\title{
CORRESPONDENCE
}

\section{Noninvasive ventilation or paradigm paralysis?}

\author{
To the Editor:
}

Current respiratory management paradigms recommend tracheotomy for ventilator-dependent patients. The review by SHNEERSON and Simonds [1] published in the European Respiratory Journal on the current use of noninvasive ventilation (NIV) in neuromuscular disorders does little to dispel this paradigm.

The authors note that "nasal and face masks are usually the first choice" for NIV interfaces, and they further note that randomised controlled trials are needed to determine outcomes for NIV and in-exsufflation, particularly in amyotrophic lateral sclerosis. The authors seem to be unaware that $>250$ long-term (mostly 24-h dependent) NIV users have been described whose main interface was a simple mouthpiece during the day and mouthpiece with plastic phalange during sleep [2]. We currently have $>600$ continuous NIV users, some for $>50 \mathrm{yrs}$, and most using a simple mouthpiece during daytime hours, yet SHNEERSON and SimONDS [1] refer to mouthpieces as "ventilatory adjuncts".

In a study of patients who had used both tracheostomy and NIV, the latter was overwhelmingly preferred for safety, quality of life and overall [3]. In another study of $>700$ ventilator users, there were significantly fewer hospitalisations and pulmonary complications in the NIV group as compared to the tracheotomy group, even though these users controlled for equivalence of pulmonary and bulbar dysfunction [4]. Despite this, SHNEERSON and SIMONDS [1] note that tracheostomy should be considered when 24-h ventilator use becomes necessary.

The article purports to review NIV yet fails to mention volume-cycled ventilators, the ventilator style used in $>15$ studies on this subject and the only style that allows users to obtain the deep breaths needed for effective assisted coughing [5]. It is not surprising that SHNEERSON and SimONDS [1] think that tracheostomy tubes are needed, as they neglected to explain how to use NIV for 24-h aid, how mechanically assisted coughing needs to be used and the concept of aiding respiratory muscle function in general.

Perhaps one way to establish the efficacy of NIV to prolong survival in a randomised trial is for one half of the 24-h NIV-dependent patients to turn off their volumecycled ventilators and asphyxiate to prove that NIV is effective. Perhaps the patients who became 24-h NIV dependent during chest infections and whose oxyhaemoglobin saturations could only be normalised by expelling airway secretions using the cough-assist device should have been left to drown in them as part of a controlled trial.

Any review on noninvasive ventilation should consider patients who become continuously dependent on noninvasive ventilation without ever developing respiratory failure or being hospitalised. The authors are further unaware of the successful pregnancies of long-term 24-h noninvasive ventilation users with vital capacities $<300 \mathrm{~mL}$ and no ability to breathe [6].

\section{J.R. Bach*, M.R. Gonçalves ${ }^{\#}$}

*UMDNJ-New Jersey Medical School, Physical Medicine and Rehabilitation, Newark, NJ, USA. \#Rehabilitation and Lung Unit, Pulmonary Medicine Dept, University Hospital of S. João, Porto, Portugal.

\section{References}

1. Shneerson JM, Simonds AK. Noninvasive ventilation for chest wall and neuromuscular disorders. Eur Respir J 2002; 20: $480-487$.

2. Bach JR, Alba AS, Saporito LR. Intermittent positive pressure ventilation via the mouth as an alternative to tracheostomy for 257 ventilator users. Chest 1993; 103: 174182.

3. Bach JR. A comparison of long-term ventilatory support alternatives from the perspective of the patient and care giver. Chest 1993; 104: 1702-1706.

4. Bach JR, Rajaraman R, Ballanger F, et al. Neuromuscular ventilatory insufficiency: the effect of home mechanical ventilator use $v s$. oxygen therapy on pneumonia and hospitalization rates. Am J Phys Med Rehabil 1998; 77: 819.

5. Bach JR. Home mechanical ventilation for neuromuscular ventilatory failure: conventional approaches and their outcomes. In: Bach JR, ed. Noninvasive Mechanical Ventilation. Philadelphia, Hanley \& Belfus, 2002; pp. 103-128.

6. Bach JR. Successful pregnancies for ventilator users. $A m J$ Phys Med Rehabil 2003; 82: 226-229.

\section{From the authors:}

We are aware that J.R. Bach has strong opinions on noninvasive ventilation in neuromuscular disease. The views expressed in our review [1] do not diverge greatly from the management he suggests. However, we differ in believing that a flexible approach is sensible and that there should be flexibility in management plans, especially for completely ventilator-dependant patients. His comments about volumepreset ventilators are not particularly relevant to European practice since pressure-preset ventilators are much more commonly used.

\section{J.M. Shneerson*, A.K. Simonds}

*Respiratory Support and Sleep Centre, Papworth Hospital, Cambridge, and Sleep and Ventilation Unit, Royal Brompton and Harefield NHS Trust, London, UK

\section{References}

1. Shneerson JM, Simonds AK. Noninvasive ventilation for chest wall and neuromuscular disorders. Eur Respir J 2002; 20: $480-487$. 